\title{
Two conceptions of voluntary action in the Nicomachean Ethics
}

\section{Daniel Wolt [}

Department of Philosophy, Faculty of Humanities and Letters, Bilkent University, Ankara, Turkey

\section{Correspondence}

Daniel Wolt, Department of Philosophy, Faculty of Humanities and Letters, Bilkent University, Bilkent 06800, Ankara, Turkey. Email: daniel.wolt@bilkent.edu.tr

Funding information

São Paulo Research Foundation, Grant/Award Number: 2016/05983-0

\begin{abstract}
It is nearly universally agreed among commentators that according to Aristotle's account of voluntary action in the Nicomachean Ethics (NE), only voluntary actions are blameworthy. I argue for a qualified rejection of this assumption: some actions that Aristotle counts as blameworthy do not meet the criteria for voluntariness set out in NE 3.1. However, in NE 3.5 and elsewhere, one finds a broader conception of voluntary action, and it is true that, for Aristotle, an action must be voluntary on this broader conception in order to be blameworthy. While the narrow conception only counts actions that are under the agent's direct control as voluntary, the broader conception includes also actions that are under the agent's indirect control. The compresence of these two conceptions in the NE is not simply a matter of sloppiness on Aristotle's part. Rather, he has good philosophical reasons for employing both.
\end{abstract}

\section{1 | INTRODUCTION}

Aristotle begins his discussion of voluntary ${ }^{1}$ action in Nicomachean Ethics (NE) 3.1 by relating it to praise and blame: by providing an account of when an action is voluntary, Aristotle means, somehow, to say something about when an agent is praiseworthy or blameworthy for an action. ${ }^{2}$ There is a question, though, about how precisely his account is meant to do this-what is the connection between an action's being voluntary on the one hand and its being praiseworthy or blameworthy on the other? Here, l'll focus specifically on the question of blame, since that also seems to be Aristotle's primary concern.

Now, it is very common to read Aristotle's remarks at the beginning of NE 3.1 as saying that (at least as far as actions are concerned) voluntariness is a necessary condition for blameworthiness. ${ }^{3}$ This suggests something like the following picture. For an action to be blameworthy, on Aristotle's view, it must meet two conditions: it must be bad in some sense (e.g., harmful in some non-trivial way), and it must be voluntary. NE 3.1 is meant to tell us about when the latter condition obtains ${ }^{4}$ and he leaves it to us to figure out when the first condition obtains. 
I think the relationship between voluntariness and praiseworthiness and blameworthiness is considerably more complicated than this picture suggests. Specifically, I think that, on Aristotle's view, some blameworthy actions fail to meet the 3.1 criteria for voluntariness. However, I do not wish unqualifiedly to reject the assumption that voluntariness is a necessary condition for blameworthiness. This is because I think that when Aristotle returns to the topic of voluntariness in NE 3.5, he employs a broader conception of voluntariness according to which for an action to be voluntary, it is enough that it have been up to ( $\dot{\varepsilon} \pi \hat{i}+$ dativus personae) the agent. I think, however, that the compresence of these two conceptions of voluntariness in the NE-a narrower one in 3.1 and a broader one in 3.5-can be made good philosophical sense of. The reason that voluntariness is closely connected to the topic of blameworthiness is that we are only blameworthy for what is, in some sense, under our control. But things can be under our control in different ways. For an action to be voluntary in the paradigmatic sense spelled out in 3.1 is for it to be under the agent's control in a quite direct way. But not all actions that are under our control are under our direct control. Hence, in 3.5, we find an expanded conception of voluntariness in order to include things that are only indirectly under our control. This expanded conception is not meant to replace the narrow one, but to complement it. ${ }^{5}$

I begin (Section 2) by providing an initial argument for thinking that, in 3.1, some non-voluntary actions are blameworthy. Many people, however, will not be willing to accept this conclusion on the grounds that it conflicts with Aristotle's remarks about the voluntary and praise and blame at the beginning of NE 3.1. Hence, I next (Section 3) examine those remarks and argue that, while they do indicate that Aristotle sees a close connection between voluntariness and praise and blame, they do not require us to attribute to him the settled assumption that only voluntary actions are blameworthy. In NE 3.5, however, things become somewhat more complicated. There it does seem that Aristotle assumes that voluntariness is a necessary condition for blameworthiness, but I argue on independent grounds (Section 4) that this is because Aristotle is employing an importantly different conception of voluntariness. I conclude (Section 5) by considering why Aristotle makes use of both conceptions.

\section{2 | THE NARROW CONCEPTION}

In NE 3.1, for an action to be voluntary, it must meet two conditions: (a) it must have its origin or starting-point (à $\rho \chi \eta ́$ ) within the agent-by which Aristotle means, roughly, that it must be done on the basis of one of the agent's desires $^{6}$-and (b) it must be done with knowledge of certain basic features of the action. ${ }^{7}$ The agent must know "who is doing [the action]; what he is doing; about what or to what he is doing it; sometimes also what he is doing it withwith what instrument, for example; for what result, for example, safety; in what way, for example, gently or hard" (1111a3-6). Aristotle sometimes refers to this list of features simply as "the particulars" of the action, as will I in what follows.

Of special concern for me here will be this latter, knowledge condition. Aristotle is explicit in 3.1, that an action that does not meet this condition does not straightaway qualify as involuntary. This is because in addition to voluntary and involuntary actions, there is a third category of actions that Aristotle calls non-voluntary. While I accept that for Aristotle involuntary actions are never blameworthy, I will argue that the category of non-voluntary actions includes some blameworthy actions. Hence, according to 3.1, it is not a necessary condition for an action to be blameworthy that it be voluntary.

To argue for this, the main issue that I will be concerned with is how large the class of non-voluntary actions is meant to be. When Aristotle first introduces the category of non-voluntary action, the kind of action that he most

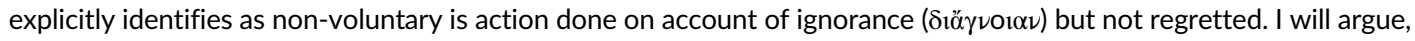
however, that this is not the only kind of non-voluntary action. Another kind is action done in culpable, nonnormative ignorance. This latter kind of action is, I think, clearly meant to be blameworthy. Hence, actions of this sort are a counterexample to the idea that, for Aristotle, only voluntary actions are blameworthy.

Let me begin by considering briefly the class of non-regretted actions that Aristotle uses to introduce the nonvoluntary. An example of the kind of case that Aristotle seems to have in mind might be the following: a passenger 
boarding a bus unwittingly steps on another passenger's foot but, upon realizing what she has done is indifferent. In this case, we may suppose, the agent acted on the basis of ignorance-the fact that she did not realize what she was doing in stepping on the other passenger's foot in part explains why she did it. But since it was not regretted, Aristotle wishes to distinguish actions like this from genuinely involuntary actions. In order for an action to qualify as fully involuntary, the agent must, in some sense, be actively opposed to it. ${ }^{8}$ These actions do not qualify as voluntary either, though, since they do not satisfy the knowledge condition.

Now, it is worth noting that the actions that Aristotle describes here are quite plausibly thought to be blameworthy. If this is right, then even the case of non-regretted actions here will constitute a counterexample to the claim that, in 3.1, voluntariness is meant to be a necessary condition for blameworthiness. However, I do not think the text is decisive in this regard. According to one popular and plausible view, ${ }^{9}$ the regret condition does not bear on the blameworthiness of the action, but rather on how we evaluate the agent's character. While it is not clear to me that this interpretation is right, it is not clear to me that it is wrong either. Hence, I will set aside the class of non-regretted actions and turn my attention to a kind of action that Aristotle introduces immediately after discussing non-regretted actions: actions done in but not on account of ignorance. These are clearly meant to be blameworthy, but I will argue that at least some such actions are non-voluntary as well.

The key passage reads as follows:

T1. Further, action caused by ignorance would seem to be different from action done in ignorance. For if the agent is drunk or angry his action seems to be caused by drunkenness or anger, not by ignorance, though it is done in ignorance, not in knowledge. ${ }^{10}(1110 b 24-27)$

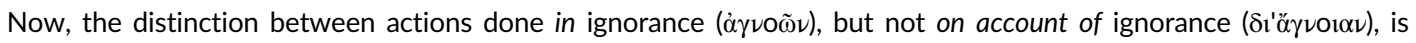
meant to be a distinction between one way in which an agent's ignorance may excuse a bad action-action done on account of ignorance-and another in which it does not-action done merely in ignorance. Hence, I take it, in agreement with most commentators, that the class of actions done merely in ignorance are sometimes culpable. It is clear that actions done merely in ignorance are not meant to be involuntary, ${ }^{11}$ but there is a question about whether they are meant to be voluntary or non-voluntary. This question, in turn, hinges upon what kind of ignorance this agent is acting with. If the agent is ignorant of the particulars, then her action cannot be voluntary (for it fails the knowledge condition) and hence must be non-voluntary. I will argue that by Aristotle's lights cases of ignorance of the particulars

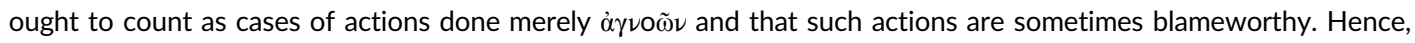
some blameworthy actions are non-voluntary. ${ }^{12}$

This is not, however, the way the passage is usually read. According to one reading which dates back to antiquity $^{13}$ and which remains popular ${ }^{14}$-l'll call it the traditional reading-the distinction in T1 between actions done on account of ignorance and those merely done in ignorance is meant to map onto a distinction that Aristotle introduces in the lines that immediately follow between ignorance of the universal and ignorance of the particular. The latter passage reads as follows:

T2. Certainly ( $\mu \dot{\nu} \nu$ oũv) every vicious person is ignorant of the actions he must do or avoid, and this sort of error makes people unjust, and in general bad. This ignorance of what is beneficial is not taken to make an action involuntary. For the cause of involuntary action is not [this] ignorance in the decision, which causes vice. It is not, in other words, ignorance of the universal, for we are blamed because of that. Rather the cause is ignorance of the particulars

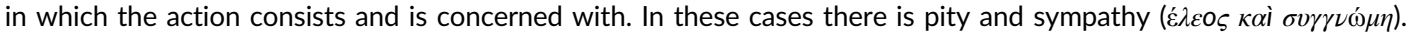


The main point that Aristotle is trying to make here, although cloaked in the language of his syllogistic, is familiar enough to philosophers today. Although actions done in ignorance of normative facts (identified here with ignorance of the universal and ignorance in the decision)-for example, the fact that it is wrong to steal to enrich oneself-are done on account of ignorance in a way, the ignorance at issue is not the sort that either excuses or makes an action involuntary. On this reading, actions done merely in ignorance are meant to correspond to actions done on account of ignorance of the universal, whereas actions done on account of ignorance are meant to correspond to actions done on account of ignorance of the particular. Since Aristotle is perfectly clear that actions done on account of ignorance of the universal are voluntary, if this reading is right, then actions done merely in ignorance will be voluntary as well.

Now, there are a number of reasons that this reading is popular. One is that it makes T1 consistent with certain remarks that Aristotle makes in 3.5 which suggest that he thinks that actions such as these are voluntary. ${ }^{15}$ Another is that it provides a way of making T1 consistent with the idea that voluntariness is a necessary condition for blameworthiness. I will have more to say about both these issues in what follows. For now, however, I shall set these considerations aside and consider what reason, apart from these, one may have to accept the traditional reading.

Since the traditional reading takes T2 to be an elaboration of the idea in T1, a natural place to begin would be to consider whether Aristotle provides any linguistic cues to indicate that. And it has been claimed that he does. The distinction in T2 is introduced with the particle combination $\mu \dot{\varepsilon} \nu$ oũv, which often has inferential force. Thus, one might think that this distinction in T2 is meant somehow to follow from what came before. ${ }^{16}$ The particle does not always have this meaning, though, and hence, this consideration is far from conclusive. It is quite common, for example, for Aristotle to use $\mu \dot{\varepsilon} \nu$ oũv resumptively-to introduce a new topic. The question, then, is whether the distinction in T2 provides the best available way of making sense of the distinction in T1.

And on this point, I concede that there is something to be said for the traditional reading. On that view, what Aristotle is calling attention to in T1 is the way in which conditions like drunkenness and anger can perniciously affect one's behavior by affecting one's normative outlook. Drunkenness, for example, diminishes one's inhibitions, and this can affect one's normative judgments in such a way that behaviors that one would clear-headedly see as wrong or imprudent while sober might appear appropriate while drunk. Anger has a similar cognitive effect. If someone is extremely angry because, say, she has just been cut off in traffic, she might judge that some form of violent retaliation is called for. When she is not so angry, though, we may suppose that she would realize that retaliating is not a good idea.

However, the traditional reading does not, in my opinion, do justice to the causal component of T1. Greek partici-

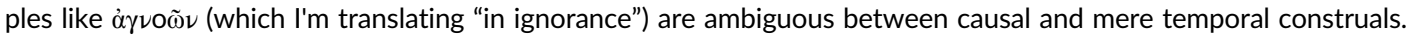
By distinguishing an action done $\gamma \nu 0 \nu$ from one done $\delta \imath^{\prime}$ 'ö $\gamma \nu 01 \alpha \nu$, Aristotle seems to be calling attention to precisely this fact: it is not enough that an action be done while ignorant in order for it to count as voluntary, the ignorance needs also to occupy a certain prominent place in the explanation of the action. It needs to count as the root cause, so to speak, of the action. The reason that actions done while drunk or angry do not qualify as involuntary is precisely because, in those cases, the ignorance is merely the downstream effect of something else. Although, in these cases, the ignorance does play a causal role, it is not the root cause of the action-the root cause is, rather, the drunkenness or the anger. ${ }^{17}$ There seems, then, to be an important difference between the distinction in T1 and the distinction in T2 that the traditional reading does not account for: whereas the distinction in T2 is a distinction between the content of two types of ignorance-normative content in the one case and non-normative content on the other-the distinction in $\mathrm{T} 1$ is a distinction between the causal role that the ignorance plays in either case.

This suggests that cases of non-normative ignorance may count among actions done in but not on account of ignorance. ${ }^{18}$ After all, non-normative ignorance can be a downstream effect of anger or drunkenness too. What might such a case look like? Suppose someone brings his young child with him to a bar and gets drunk. Being drunk, he then unwittingly leaves the child behind when he goes home. In this case, the agent is ignorant of the particulars (he does not know what he is doing at the time-namely, leaving his child behind), so the action is not voluntary, but it does not seem that it would qualify as "on account of ignorance" since the ignorance is simply a downstream effect 
of his drunkenness. Hence, it seems that actions such as this ought to be included among actions done in but not on account of ignorance, and hence, they should be non-voluntary. ${ }^{19}$

But would an action such as this be culpable? Intuitively, it seems that it would. If the drunken ignorance was a result of culpable, reckless behavior, it seems that the ignorant action may be culpable as well. And there is evidence that Aristotle himself would accept that such actions are culpable. In NE 3.5, in a passage that I shall discuss more below $(1113 \mathrm{~b} 31-1114 \mathrm{a} 3=\mathrm{T} 6$ ), Aristotle seems to accept the principle that if a bad action is done on the basis of ignorance which is itself caused by culpable behavior, the agent is culpable both for the action and for the ignorance. $^{20}$

On balance, then, I take it that we have very good reason to believe that T1 classifies at least some culpable actions as non-voluntary. Nonetheless, some will be reluctant to accept this conclusion since it is thought that a necessary condition for an action to be blameworthy is that that action be voluntary. ${ }^{21}$ To address this worry, I turn my attention now to the evidence for the latter assumption. While there may be some evidence for it in 3.5 , I suggest that, in NE 3.1, we do not find good reason for reading that assumption into that chapter.

\section{3 | NE 3.1, 1109B30-35 ON THE RELATIONSHIP BETWEEN VOLUNTARINESS AND BLAMEWORTHINESS}

The reason that most commentators assume that a necessary condition for an action to be blameworthy is that it be voluntary, I take it, ${ }^{22}$ that they read Aristotle's remarks at the very beginning of 3.1 as asserting that very claim. The strength of this textual evidence, however, tends to be greatly overstated. The remarks in question, I suggest, are merely programmatic and are not plausibly read as reflecting a settled view. Rather, Aristotle is merely observing an association that will motivate the subsequent investigation:

T3.Virtue, then, is has to do with feelings and actions. These [feelings and actions] receive praise or blame if they are

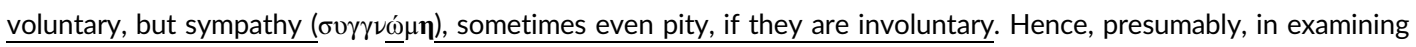
virtue we must define the voluntary and the involuntary. This is also useful to legislators, both for honors and corrective treatments. (1109b30-35)

The main issue here concerns how to interpret the key lines (30-32), which I have underlined. Most commentators interpret them to be saying (at least) that only voluntary actions are praiseworthy or blameworthy. ${ }^{23}$ While it is worth noting that this is not at all required by Aristotle's actual language, I do think this reading contains a certain amount of plausibility. On balance, however, I do not think that it is the best available way of reading the passage.

Notice first that Aristotle does not say that virtuous and vicious voluntary actions are praiseworthy and blame-

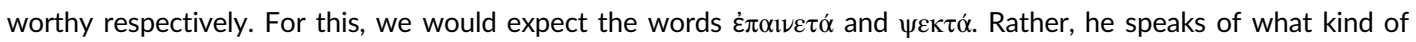

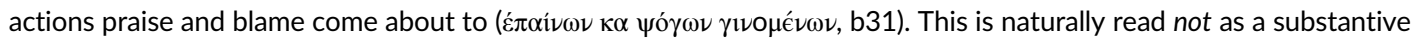
normative claim about when praise and blame are appropriate, but rather as a descriptive claim about moral practice. ${ }^{24}$ This suggests that a more modest and, to that extent, preferable reading of the key lines would take Aristotle to merely be citing a fact about ordinary moral practice in order to indicate a connection between voluntariness and praise and blame, the precise nature of which is to be worked out over the course of Aristotle's own discussion.

There are several quite strong considerations in favor of the latter, weaker reading. First, and most obvious, on this reading, Aristotle is employing his standard procedure for approaching a problem: begin by stating the "reputable

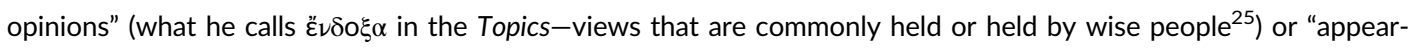

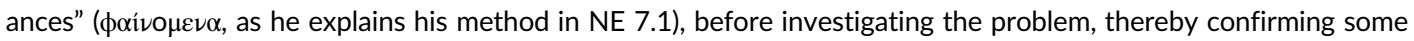
$\ddot{\varepsilon} \nu \delta \circ \xi \alpha$ or appearances and refining or disconfirming others. In the Eudemian counterpart to NE 3.1 (EE 2.6-2.9), this is very obviously the procedure that Aristotle uses. ${ }^{26} \mathrm{It}$ makes sense that he would use the same procedure here, albeit in a somewhat more abbreviated form. 
Second, the weaker reading better suits the context within which the key lines occur. The reason Aristotle makes those remarks about the relationship between voluntariness and praise and blame in the underlined portion of the text is in order to support the claim in the lines that precede that defining the voluntary and involuntary is important for purposes of investigating virtue and vice. In order to do this, he does not need a claim as strong as the stronger reading attributes to him. He only needs to observe that the two topics are importantly connected. He does not need any very precise account of how they are in fact connected.

Finally, if Aristotle's claim that "voluntary actions are praised and blamed" means that only voluntary actions are

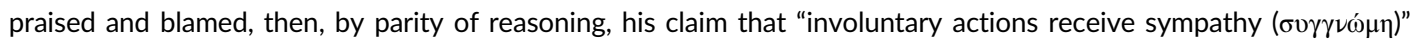
ought to mean that only involuntary actions receive sympathy, but this is very clearly not his view, as he makes explicit later on in the chapter. After concluding that what he calls "mixed" actions-roughly, actions done begrudgingly due to undesirable circumstances-are voluntary, Aristotle hastens to point out that they still may receive sympathy and may even be worthy of pity or even praise (1110a19-26). If, then, Aristotle does not think that sympathy is properly confined to involuntary actions, as the stronger reading suggests, why should we assume that he thinks that blame is only confined to voluntary actions, given the strong evidence to the contrary that I have set out so far?

I conclude that we do not have good reason for reading the assumption that voluntariness is a necessary condition for blameworthiness into NE 3.1 and in fact we have very good reason to think that it is not. I am not denying, of course, that Aristotle sees voluntariness as closely connected to praise and blameworthiness. It may even be that on Aristotle's considered view an action needs to be voluntary in some sense for it to be blameworthy. All I am saying for now is that we do not have good reason for thinking that all blameworthy actions need to satisfy 3.1's criteria for voluntariness. In the next section, I will turn to 3.5 and suggest that there Aristotle employs a broader conception of voluntariness, and it is true that an action needs to be voluntary in this latter sense in order to count as blameworthy.

\section{4 | THE BROAD CONCEPTION}

Whereas NE 3.1 was concerned with voluntariness as it applies to actions, 3.5 is concerned primarily with voluntariness as it applies to states of character. I shall argue for two main points. The first is that for a state of character to be voluntary in 3.5, it is enough for that state of character to be up to the agent. This represents a kind of broadening of how Aristotle is thinking about voluntariness since, in 3.1, there are actions that are up to us but which are not voluntary. The second point I will argue for is that, in 3.5, Aristotle applies this broader conception of voluntariness to actions as well. As a result, the very same actions done in culpable, non-normative ignorance at issue in T1 above, where they were non-voluntary, are counted in 3.5 as voluntary.

The central issue here concerns the relationship between the voluntary and what is up to us ( $\dot{\varepsilon} \phi \dot{\eta} \dot{\mu} \tilde{\imath} \nu, \dot{\varepsilon} \pi \dot{i}+$ dativus personae). Unlike in 3.1, where the concept of what is up to us to us plays almost no role (more on that in a moment), the concept of what is up to us takes primacy of place in 3.5 from the very beginning of the chapter.

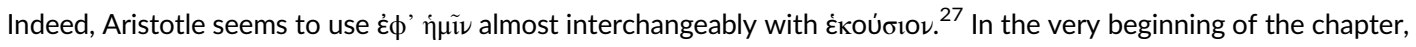
for example, Aristotle, after some brief transitional remarks, sets out an argument for the claim that "virtue is up to us, and so also, in the same way, is vice" (1113b6-7) or that "being decent or base is up to us" (1113b13-14). The lines that immediately follow suggest that he takes this conclusion to imply (at least) that virtue and vice are voluntary: "The claim that 'no one is voluntarily bad or involuntarily blessed' would seem to be partly true but partly false. For while certainly no one is involuntarily blessed, vice is voluntary" (1113b16-17). There is nothing here or in the context to suggest that Aristotle means to be shifting topics back to the voluntary, and the reader is left with the impression that the conclusion that vice is voluntary is meant to simply be a restatement of the conclusion that vice is up to us.

This impression is further strengthened when one reads on and finds a further argument, apparently for the same thesis, but this time formulating the conclusion in terms both of the voluntary and in terms of what is up to us: 
T4. If this is not so, we must dispute what has been said, and we must deny that a human being is a principle, begetting actions as he begets children. But if what we have said appears true, and we cannot refer back to other principles apart from those that are up to us, those things that have their principles in us are themselves up to us and voluntary. (1113b19-21).

This last passage is especially significant because it suggests that if something has its origin in us it is both up to us and voluntary. This, however, is at odds with the picture we seem to find in 3.1. There, the sole occurrence of غ̇ंí with the dative of person occurs in the context of a discussion of mixed actions where Aristotle infers that an action is up to the agent from the claim that that action has its origin in the agent (1110a15-18). There is thus a connection between an action's being up to us and having its origin in the agent. However, the fact that an action has its origin in the agent does not imply that the action is voluntary. For the action to be voluntary, according to 3.1 , it must also satisfy the knowledge condition, as we saw in Section 1. A natural way of understanding T4 then would be to think that Aristotle is here speaking of the voluntary somewhat loosely and when he concludes at $1113 \mathrm{~b} 21$ that virtue

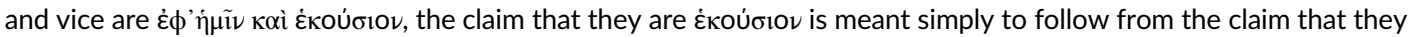
are $\dot{\varepsilon} \phi ' \dot{\eta} \mu \tilde{\mathrm{i}} .^{28}$ Indeed, when one reads on through the whole battery of arguments that Aristotle provides for thinking that virtue and vice are up to us and voluntary, one is hard-pressed to find a single indication that these two notions are meant to come apart. Rather he switches back and forth freely from talking about these things being up to us and their being voluntary.

The fact that, in 3.5, Aristotle seems to equate something's being up to us with that thing's being voluntary suggests that the knowledge condition does not play the same role in that chapter as it did in 3.1. This impression seems to find confirmation towards the end of the chapter when Aristotle sums up by commenting on the difference between voluntariness as applied to actions and voluntariness as applied to states of character.

T5. Actions and states, however, are not voluntary in the same way. [i] For we are in control of actions from the beginning to the end, when we know the particulars. [ii] With states, however, we are in control of the beginning, but what the cumulative effect of particular actions will be is not clear, any more than with sicknesses. Nonetheless, since it was up to us to exercise a capacity either this way or another way, states are voluntary. (1114b30-1115a3)

Here, Aristotle identifies two differences between the way in which actions are voluntary and the way in which states of character are voluntary: one pertaining to the kind of control that the agent has, another relating to the agent's epistemic condition. These two are manifestly meant to be closely related. In part [i], the phrase "when we know the particulars" is meant, I take it, as a partial explanation of what came before, "we are in control of actions from the beginning to the end." The thought here, I think, is intuitive. To say that someone is in control of (кúpros) an action, in Aristotle's mind, implies that the agent did the action intentionally, and this requires that the agent know what he is doing when he performs the action. ${ }^{29}$ In part [ii], Aristotle points out that the person who voluntarily acquires a given state of character need not have grasped that he was acquiring that state of character-he need not have known that he was acquiring that state of character. The reason that the state of character is voluntary has simply to do with the fact that the agent controlled the starting-points, by which Aristotle is referring to the actions that produced that state of character. This coheres quite well with what Aristotle says earlier in the chapter, when he points out that even bodily diseases may be voluntary if they are the result of, for example, negligence or recklessness. Presumably, in the cases Aristotle has in mind, he is not thinking of someone who intentionally makes herself sick (or for that matter, someone who makes herself sick knowing that she is doing so), but rather someone who becomes sick in part precisely because she does not think about the consequences of her actions. The reason, however, that Aristotle is willing to credit the agent with responsibility even in these cases is that the agent controls the starting point-the voluntary actions that produced the state of character.

Now, it is natural to construe T5 as saying that, unlike states of character, actions must be under the agent's control from start to finish in order to count as voluntary. Control from start to finish is a type of direct control. ${ }^{30}$ Hence, 
this passage might be read to suggest that voluntary actions are always under the agent's direct control. There is, however, good reason for doubting that Aristotle means to say that all actions are under the agent's control from start to finish. Mainly, this would be an extraordinarily strong requirement on voluntariness. Only very simple actions seem to fit the description of being under the agent's control from start to finish (for example, raising my arm). Suppose, for example, that I intentionally break a window by throwing a stone at it. Breaking the window is an action that I have done, in this case. And, given the criteria in NE 3.1, it seems to be a voluntary action-I knew the relevant particulars, and, crucially, the starting-point is in me. But there is at least a part of the action that I do not control, namely, the stone's movement once it has left my hand. Aristotle himself seems to have something like this case in mind just a few lines earlier in 3.5 (1114a7-29) when he comments that fact that one cannot control the movement of the stone once one has released it, does not mean that one is not responsible for the consequences of throwing the stone. I take it, then, that it is better to take T5 to be talking merely about paradigmatic cases of voluntary actions and character states respectively, without taking any stance on the question of whether the same considerations that make some character states voluntary could make some actions voluntary as well.

So, is there reason to believe that one may exercise indirect control over actions? First, we ought to consider what it would be to exercise control over an action in an indirect way. I think we have already discussed a case like this when we discussed actions done in drunken ignorance. Aristotle returns to cases like this in 3.5 in the context of the series of arguments for the view that both virtue and vice are voluntary, that I mentioned earlier. One of Aristotle's arguments adverts approvingly to existing legislative practices. If vice were not up to us, it would be absurd for legislators to impose corrective treatments for it. But legislators do impose such treatments and these treatments are effective, which indicates that vice is in a way up to us and voluntary (1113b21-30). He goes on to point out that "legislators also impose corrective treatments for one's ignorance itself, if the agent seems to be responsible for the ignorance" (1113b30-31).

T6. A drunk, for instance, pays a double penalty; for the starting-point is in him, since he controls (кúpros) whether he gets drunk, and his getting drunk causes his ignorance. They [sc. legislators] also impose corrective treatment on someone who [does a vicious action] in ignorance of some provision of the law that he is required to know and that it is not hard [to know]. And they impose it in other cases likewise for any other ignorance that seems to be caused by the agent's inattention; they assume it is up to him not to be ignorant, since he controls whether he pays attention. (1113b31-1114a3)

When Aristotle speaks of the drunk paying a double penalty, he presumably has in mind a case in which an agent's drunkenness causes a kind of ignorance and that ignorance, in turn, causes him to do something in violation of the law. The agent in this case is culpable, both for the ignorance and for the culpable behavior that the ignorance caused. ${ }^{31}$ I submit that the cases of drunken ignorance that Aristotle is alluding to here are of precisely the same sort as those that we encountered in T1-like the drunkenly ignorant actions of T1, here the ignorance at issue also includes ignorance of the particular. There are two considerations that support this. First, Aristotle seems to intend here a contrast between the kind of ignorance at issue in the cases of drunkenness that he has in mind and the ignorance at issue in the cases of negligence that he speaks of in the second part of the passage. The latter sort of ignorance is clearly normative-ignorance of what the agent is required or prohibited from doing by the law. This suggests that the kind of ignorance at issue in the first part of the passage is non-normative. Second, and, I think, more strongly, Aristotle seems to be referring here to a law enacted by Pittacus, the sixth-century tyrant of Mitylene and one of the Seven Sages, and elsewhere Aristotle provides somewhat more detail about the law, indicating that the ignorance at issue is indeed ignorance of the particulars. In the Rhetoric, Aristotle uses Pittacus' law concerning drunkenness in an example. If one wishes to rebut an enthymeme according to which "allowances ought to be made for drunken offenders, since they know not what they are doing" one way to refute it would be by pointing out the undesirable consequence that the revered "Pittacus, then, deserves no approval or he would not have prescribed specially severe penalties for offences due to drunkenness" $32(2.25,1402 \mathrm{~b} 8-12))^{33}$ These remarks clearly suggest that at least one 
kind of ignorance that is meant to be covered in T6 is ignorance of what the agent is doing, and this is one of the kinds of ignorance that counts as ignorance of the particulars.

Thus, the very actions that Aristotle is referring to in T6 would seem to fit the description of actions that the agent controls indirectly. The agent does not directly control them, because he is ignorant of the particulars at the time of acting. Nonetheless, Aristotle is willing to say that the agent is in control of these actions since that agent was in control of getting drunk and that these actions are up to the agent. Since, as I already noted, NE 3.5 seems to identify what is up to us with what is voluntary, this implies that these actions are voluntary. There is, thus, a clear disagreement between 3.5 on this point and 3.1. This disagreement seems to be explained by the fact that the two chapters are operating with importantly different conceptions of voluntariness. The 3.1 conception of voluntariness is narrower in that it requires that the action both be up to us and be done with a certain kind of situational awareness. The conception in 3.5 is broader in the sense that it counts anything that is up to the agent as voluntary.

I hope it is clear already that I am not suggesting that this is a matter of simple inconsistency on Aristotle's part. After all, the broad conception of voluntariness in a way builds upon the narrow conception in 3.1. In order for an action or a state of character to be voluntary in the broad sense, it needs either itself to be voluntary in the narrow sense or to be caused in the suitable sort of way by an action that is voluntary in the narrow sense. I suggest, then, that, in 3.5, Aristotle introduces a conception of voluntariness in terms of what is up to us that, although closely related to the conception in 3.1, is distinct and theoretically useful. On the picture that I am suggesting, the whole of 3.1-3.5 consists in successive treatments of distinct but closely related topics. Just as, for example, the discussion of decision in 3.2 is distinct but importantly related to the discussion in 3.1 , the discussion in 3.5 is distinct but importantly related to the discussion in 3.1 .

\section{5 | WHY TWO CONCEPTIONS?}

The question I wish to turn to now is why it is philosophically useful for Aristotle to introduce and employ the broader conception. Part of the answer to this is, I think, already clear. As we saw in T5, voluntariness has crucially to do with control. Since there is a distinction between being in direct control of something and being in control tout court (where the latter includes the possibility of indirect control), it makes sense that there should be a distinction between one conception of voluntariness as direct control and another as control tout court. I think, however, that there is another reason that the broader conception is useful that is seen in NE 3.12. There Aristotle treats voluntariness as a scalar notion in order to address questions about how much blame certain character states and their corresponding actions bear. Voluntariness as a scalar notion only makes sense, I suggest, on the broader conception. Hence, the broader conception allows Aristotle to provide a kind of analysis that the narrower one does not.

Let me begin with some context. After concluding his discussion of voluntariness and related topics in 3.1-3.5, Aristotle begins discussing each of the particular virtues and their contraries, first discussing courage and cowardice in 3.6-3.9 and then discussing temperance and self-indulgence in 3.10-3.12. But while Aristotle has already concluded that the virtues and vices in general are voluntary, it is clear that he intends his discussions of the particular virtues in part to reinforce this conclusion. ${ }^{34}$ This, presumably, is one of the reasons that in 3.12 Aristotle takes up the question of the relative voluntariness of cowardice, self-indulgence, and their respective actions.

He begins by offering some considerations that suggest that cowardice is less voluntary than self-indulgence. ${ }^{35}$ Although Aristotle has not yet made clear that one voluntary thing may be more or less voluntary than another voluntary thing, ${ }^{36}$ it is easy to make sense of this idea in light of the conception of voluntariness as control that we saw in 3.5. After all, control comes in degrees-for example, I may have some control over my physical health, but I have much more control over, for example, what clothes I wear. It is also clear why Aristotle should wish to raise the question of the relative voluntariness of one state to another. He reasonably recognizes that not all blameworthy states of character are equally blameworthy. And if one wishes to make finer-grained determinations between which of 
two blameworthy states is more blameworthy, one consideration that bears on this is how much control the agent has over that state.

This fits quite well with the considerations that Aristotle actually offers for thinking that cowardice is less voluntary than self-indulgence. He points out, for example, that circumstances in which to practice the activities that bring about courage-war-are less common than the circumstances under which one practices the activities that bring about temperance. This suggests that there is a greater element of chance involved in whether one develops courage than in whether one develops self-indulgence. To put it differently, one has less control over whether one becomes cowardly than over once becomes self-indulgent. Hence, Aristotle concludes that courage is less voluntary than selfindulgence.

What is most important for our purposes, however, is that Aristotle goes on to apply the scalar conception of voluntariness to actions as well:

T7. However, cowardice seems to be voluntary differently than particular cowardly actions. For cowardice itself involves no pain, but the particular actions disturb us because of the pain [that causes them ${ }^{37}$ ], so that people actually throw away their weapons and do all the other disgraceful actions. That is why these actions even seem to be forced. For the intemperate person the reverse is true. The particular actions are voluntary (for they are done on the basis of appetite and hence, desire); but the whole condition is less voluntary [than the actions], since no one has an appetite to be intemperate. (1119a27-33)

In the latter part of the passage, we find the clearly expressed idea that intemperance is less voluntary than intemperate actions ( $\tau$ ò $\delta^{\prime}$ ö $\left.\lambda \nu \tilde{\eta} \tau \tau o \nu, 32\right)$. Moreover, this claim is meant to be the inverse of the claim about cowardice and cowardly actions ( $\dot{\alpha} \nu \alpha \dot{\alpha} \alpha \alpha \lambda \nu, 31$ ); hence, when Aristotle says at the beginning of the passage that cowardice is voluntary differently than cowardly actions, we may suppose that what he means is that cowardice is less voluntary than particular cowardly actions. ${ }^{38}$ When we put these two claims together with the claim established earlier that cowardice is less voluntary than self-indulgence, what results is something of a scale: self-indulgent actions are more voluntary than self-indulgence, which is more voluntary than cowardice, which is more voluntary than cowardly actions. A straightforward implication of this is that self-indulgent actions are more voluntary than cowardly actions. The account of voluntary action in 3.1, however, cannot accommodate the idea that voluntariness comes in degrees. There an action is voluntary if and only if it meets the two conditions that Aristotle sets down for it to be voluntary. Either an action meets these two criteria or it does not; there does not appear to be room for degrees of voluntariness. Why, moreover, it is useful to employ a scalar notion of voluntariness is, I think, clear: because it bears on the question of how much blame an agent bears for a given state or action.

\section{6 | CONCLUSION}

If what I have argued is right, the answer to the question of how Aristotle's account of the voluntary is meant to tell us about when someone is praiseworthy or blameworthy for something is considerably more complex than commonly appreciated. This is because Aristotle's thinking about voluntariness itself is considerably more complex than commonly appreciated. Voluntariness for Aristotle has crucially to do with control. Control, however, comes in different varieties. When an action is voluntary in the sense spelled out in NE 3.1, the agent exercises a kind of direct control over the action. However, one may be in control of something-an action or something else-without being in direct control of it. Hence, in 3.5, we find an expanded notion of voluntariness meant to include these cases. The fact that Aristotle's treatment involves these two conceptions, thus, should be viewed not as a flaw-not as an instance of sloppy inconsistency-but rather as a virtue-the complexity in Aristotle's discussion mirrors the complexity in the subject matter. The broad conception of voluntariness is also useful addition to Aristotle's philosophical toolkit, as it 
allows him to speak of degrees of voluntariness and thereby approach questions that have to do with how much blame an agent bears for a given action or character state. ${ }^{39}$

\section{ORCID}

Daniel Wolt (iD) https://orcid.org/0000-0003-4815-3789

\section{ENDNOTES}

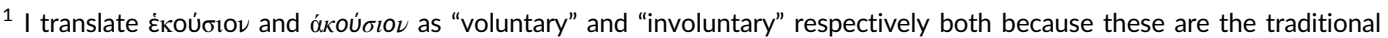
translations and because I think they are the English words that best (if imperfectly) fit the Greek terms. For a defense of these translations, see Meyer (1993, pp. 9-14).

2 See NE 3.1, 1109b30-35, discussed in Section 2 below.

3 See, for example, Bobzien (2014, p. 84), Echeñique (2014, pp. 94-95), Echeñique (2012, p. 23), Meyer (1993, pp. 52 and 111), Roberts (1989, p. 23), Englert (1987, p. 75), Sorabji (1980, p. 111), Irwin (1980, p. 125), Kenny (1979, p. 28), and Bondeson (1974, p. 59). The only commentators who I am aware of who directly question whether voluntariness is a necessary condition for blameworthiness are Siegler (1968) and Curren (1989, pp. 265-266).

${ }^{4}$ Of course, most the chapter is devoted to defeaters of voluntariness, but I take it that voluntariness is the primary notion, and the discussion of the defeaters of voluntariness is simply the slightly unusual way that Aristotle tries to get at what voluntariness is.

5 The terminology that I shall use throughout of a "narrow" and a "broad" conception is, perhaps, imperfect since it does not in and of itself indicate that the narrow conception is in a way primary (since a necessary condition for some action to be voluntary in the broad sense is for it either to be itself or to be causally related in the right way to an action that is voluntary in the narrow sense). Nonetheless, I think it is the best available terminology because it captures the key point which is that the one conception is more restrictive (and the other less) about what counts as voluntary.

6 See, for example, 1110a15-17 and 1111a25-b3.

7 See 1111a22-24, quoted below.

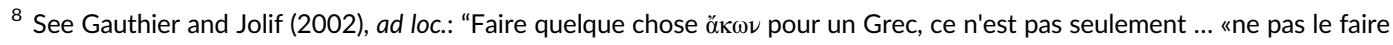
exprès», c'est le faire "malgré soi», «à contre-cœur»; cela implique chez le sujet une répugnance positive pour l'acte qu'il accomplit ainsi." Cf. Kenny (1979, p. 53). It is worth noting, however, that there still may be something blameworthy in the vicinity. It may be, for example, that, in my example case, the agent's indifference to having stepped on the other passenger's foot is an expression of a culpable character state for which the agent is responsible. I shall discuss the issue of responsibility for character states later.

9 See, for example, Irwin (1999, p. 203); cf. Chappell (1995, pp. 23-24).

10 All translations are from Irwin (1999) with minor modifications unless otherwise noted.

11 The only commentator who I am aware of who suggests otherwise is Siegler (1968), but that is simply because he wrongly fails to distinguish between involuntary and nonvoluntary.

12 On this, I agree with Curren (1989, p. 265), who, however, does not offer any argument for this reading.

13 It is endorsed by the Anonymous Paraphrast (144, 6-31) and considered by Aspasius (63, 32-33), who, however, is unsure about it.

${ }^{14}$ For more recent proponents of this reading, see, for example, Brewer (1836, p. 90), Grant (1866, Vol. 2, p. 11), Ramsauer (1878, p. 139), Stewart (1892, pp. 234-235), Gauthier and Jolif (2002, pp. 182-183), Daube (1969, pp. 134-139), Urmson (1991, pp. 46-47), and Echeñique (2012, pp. 167-168).

15 This is appealed to, for example, by Aspasius (63, 25-32), Dirlmeier (1956, p. 325), Broadie (2002, pp. 40 and 313), and Muñoz (2002, pp. 122-123), inter alios.

16 A point made by Meyer (1993, pp. 177-178) and Echeñique (2012, p. 168), although the former rightly concludes, on balance, that this is not the right way of understanding the passage.

17 This reading finds some support from similar remarks that Aristotle makes in EE 2.9. There Aristotle specifically says that in order for ignorance to make an action involuntary, that action must be done on account of ignorance, "not incidentally"

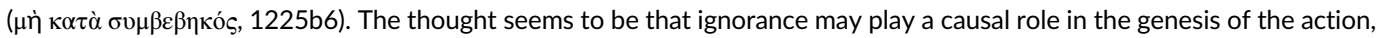


but that action may still fail to count as involuntary if the ignorance does not occupy the right kind of causal role. I take it that this is what Aristotle means when, later on in the same chapter, he says that if an agent has knowledge but does not

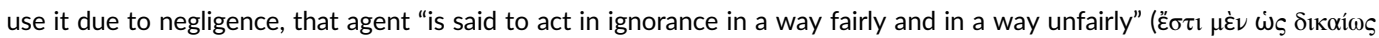

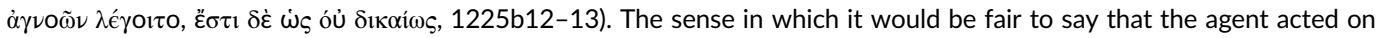
account of ignorance, I take it, is that the ignorance is a part of the whole picture that explains why the agent acted as he did, but the sense in which it would be unfair to say this is that it is misleading. To say that the agent acted on account of ignorance is to imply that the ignorance is the ultimate explanans, which is not true in the case in which negligence caused the ignorance. (The construal, however, of 1225b12-13 is controversial; see Woods, 1992, ad loc.)

18 I agree on this point with Broadie (1991, pp. 147-148) and Klimchuk (2003, pp. 230-231).

19 Further support for the idea that such actions would be non-voluntary is found in NE 5.8 (the relevance of which is called attention to by Meyer, 1993, pp. 177-179). There, Aristotle returns briefly to the topic of voluntariness and again draws a distinction between actions done in ignorance versus those done merely on account of ignorance. Importantly, however, he classifies both types as involuntary (1136a5-7). It is easy to reconcile this with the claim that they are non-voluntary-we can simply take him to be speaking somewhat more loosely in 5.8 than in 3.1 (this makes sense given that 5.8 is concerned with the jurisprudential matter of categorizing different kinds of torts). It is not easy, however, to reconcile this with the reading according to which such actions are voluntary.

${ }^{20}$ Later on, of course, I shall argue that the pictures we get in NE 3.1 and NE 3.5 differ with respect to what is necessary for an action to be voluntary, but that does not undermine my point here. My point is simply that 3.5 provides evidence that Aristotle thinks that actions are culpable which are the direct result of culpable ignorance.

21 Roberts (1989, p. 34, n. 4), for example, grants that "Aristotle does not explicitly say that an ignorant drunken action is voluntary" but nonetheless concludes that such an action is voluntary on the grounds that such actions are presumably blameworthy according to Aristotle. Broadie (1991, pp. 175-176, n. 26) concludes that these actions are voluntary as well but purports to find textual support from this beyond the putative textual support for thinking that all blameworthy actions are voluntary. She points out, correctly, that at 1111a19-23 Aristotle indicates that actions done in ignorance are not involuntary. Somewhat bizarrely, though, she takes this to be evidence that they are in fact voluntary since in that passage Aristotle "recognizes only two categories," the voluntary and the involuntary. It is true that Aristotle in the passage in question only explicitly mentions these two categories, but it is simply false that his formulation implies that all actions must fall into one or the other. On the contrary, it is perfectly clear that an action could fail to satisfy either set of criteria, namely, an action which is not done on account of ignorance but which is also not done with knowledge of the particulars, which is precisely the kind of action that we are concerned with.

22 The assumption that voluntariness is a necessary condition for praise and blame is so ubiquitous that few bother to defend it beyond adverting to these lines. Many fail to do even that.

${ }^{23}$ See, for example, Stewart (1892, vol. 1, p. 222), Kenny (1979, p. 28), Englert (1987, p. 75), Meyer (1993, pp. 1 and 52), Klimchuk (2003, p. 233), Heinaman (2009, p. 492), Echeñique (2012, pp. 5, 21, 23, and 68), and Bobzien (2014, p. 84).

${ }^{24}$ I do not, of course, think that this settles the question. It is possible that Aristotle simply accepts the fact that praise and blame is in fact attributed to voluntary actions to indicate that praise and blame is only appropriate for voluntary actions. But I think, in either case, this text does not indicate that Aristotle thinks that.

25 See 1.1, 100a21-23.

26 The whole of EE 2.7, for example, consists in a series of arguments relying on reputable premises which serves to draw out the issues that need to be investigated in order to understand the voluntary.

${ }^{27} \mathrm{Now}$, if I am right that Aristotle is using these terms interchangeably in this chapter, then that would imply that he is speaking somewhat loosely. After all, there are many actions that are up to me but which are not my voluntary actions, because I have not done them. For example, it is up to me to run out of this room right now, but since I will not do that,

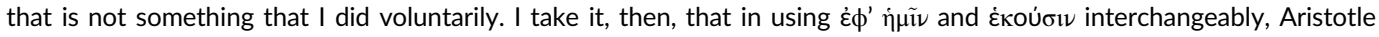
means to be only referring to actions and states of character that have already been brought about.

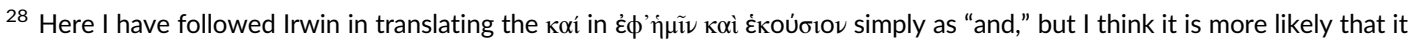
is meant to be epexegetic, making a more appropriate translation "up to us, i.e. voluntary."

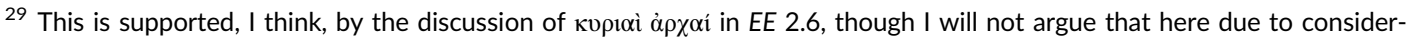
ations of length. However, I do discuss this issue in Wolt (2019).

${ }^{30}$ It is, of course, not the only type. One might directly control only a part of an action. In this case, one would exercise direct control over the action, without controlling the action from start to finish.

31 On this point, see Klimchuk (2003, pp. 229-230).

32 Translation from Roberts (1986). 
33 The only other information concerning Pittacus' law that we have comes from Politics 2.12, 1274b18-23 and Diogenes Laertius I.76. Neither text mentions ignorance.

34 As Meyer (1993, p. 45) points out.

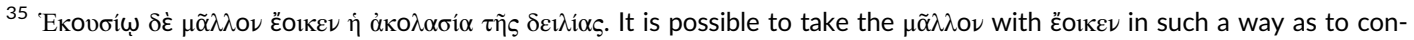
strue Aristotle to be making only the claim that self-indulgence only seems more voluntary than cowardice. There are several considerations that speak against this reading, however. First, a few lines later at 1119a24-25, we get $\mu \tilde{\alpha} \lambda \lambda$ ov $\delta \dot{\eta}$

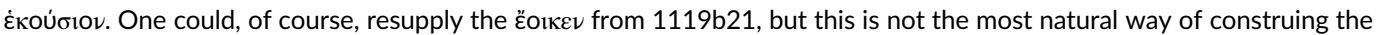
sentence. Moreover (and more significantly), the considerations that Aristotle goes on to offer over the course of the chapter are not considerations that rely (just) on how things appear, but rather on non-obvious points that Aristotle himself argues for elsewhere.

${ }^{36}$ The thought that some voluntary things are more voluntary than others is, perhaps, implicit in Aristotle's remark in 3.1

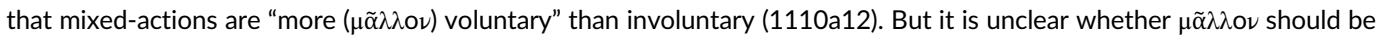
construed there as "more" or "rather." The latter is the alternative preferred by all the translations with which I am aware, and this seems to me to be right.

37 That is, the pain involved in the fear that causes such actions.

${ }^{38}$ Although restrictions of length make it impossible to explore the issue fully here, it is worth pointing out that the broad conception of voluntariness as I have construed it seems to fit well with the considerations that Aristotle provides here for thinking that cowardice is more voluntary than cowardly actions and that self-indulgence is less cowardly than selfindulgent actions. As Aristotle suggests here, pain is an indication of the presence of some force (see also EE 2.7, 1223a30-35, 1223b19-20, 2.8, 1224a30-31, 38, 1224b15-23, NE 3.1, 1110b11-12, 18-24, 1111a32-33; cf. MM 1.12, 1188a2-3, Phys. 5.6, 230b3-8, Met. $\Delta .5$, 1015a26-33, Rhet. 1.10, 1370a11-12). When an action is forced tout court, it is not under the agent's control. Hence, although Aristotle does not accept that cowardly actions are forced tout court, the fact that they nonetheless involve force in a way is a reason to think that the agent has diminished control over them. This account also explains, mutatis mutandis, why self-indulgent states of character are less voluntary than selfindulgent actions.

39 I gratefully acknowledge support from the São Paulo Research Foundation (grant no. 2016/05983-0) and the University of São Paulo for the project of which this essay is a part. This paper benefited from thoughtful questions and comments from Mitzi Lee, Hendrik Lorenz, Marco Zingano, and audiences at the University of Pennsylvania, the University of São Paulo, and the University of Colorado at Boulder.

\section{ORCID}

Daniel Wolt (iD) https://orcid.org/0000-0003-4815-3789

\section{REFERENCES}

Bobzien, S. (2014). Choice and moral responsibility in Nicomachean Ethics III 1-5. In R. Polansky (Ed.), The Cambridge companion to Aristotle's Nicomachean Ethics (pp. 81-109). Cambridge, England: Cambridge University Press.

Bondeson, W. (1974). Aristotle on responsibility for one's character and the possibility of character change. Phronesis, 19, 59-65. https://doi.org/10.1163/156852874X00086

Brewer, J. S. (1836). The Nicomachean Ethics of Aristotle. Oxford, England: Henry Slatter.

Broadie, S. (1991). Ethics with Aristotle. Oxford, England: Oxford University Press.

Broadie, S. (2002). Commentary. In S. Broadie, \& C. Rowe (Eds.), Aristotle, Nicomachean Ethics (pp. 261-452). Oxford, England: Oxford University Press.

Chappell, T. D. J. (1995). Aristotle and Augustine on freedom. New York, NY: Palgrave Macmillan.

Curren, R. (1989). The contribution of Nicomachean Ethics iii 5 to Aristotle's theory of responsibility. History of Philosophy Quarterly, 6, 261-277.

Daube, D. (1969). Roman law: Linguistic, social, and philosophical aspects. Edinburgh, Scotland: Edinburgh University Press.

Dirlmeier, F. (1956). Aristoteles, Nikomakische Ethik. Berlin, Germany: Akademie Verlag.

Echeñique, J. (2012). Aristotle's ethics and moral responsibility. Cambridge, England: Cambridge University Press.

Echeñique, J. (2014). Aristotle's appraisability compatibilism and accountability incompatibilism. In P. Destrée, R. Salles, \& M. Zingano (Eds.), What is up to us? Studies on agency and responsibility in ancient philosophy (pp. 91-106). Sankt Augustin, Germany: Akademia Verlag.

Englert, W. G. (1987). Epicurus on the Swerve and voluntary action. Atlanta, GA: Scholars Press. 
Gauthier, R. A., \& Jolif, J. Y. (2002). L'Éthique À Nicomaque: Tome II-Première Partie, Commentaire, Livres I-V. Louvain-LaNeuve, Belgium: Peeters.

Grant, A. (1866). The ethics of Aristotle: Illustrated with essays and notes (Vol. 2). London, England: Longmans, Green, \& Co.

Heinaman, R. (2009). Voluntary, involuntary, and choice. In G. Anagnostopoulos (Ed.), A companion to Aristotle (Blackwell Companions to Philosophy) (pp. 483-497). Oxford, England: Wiley-Blackwell.

Irwin, T. (1980). Reason and responsibility in Aristotle. In A. O. Rorty (Ed.), Essays on Aristotle's ethics (pp. 117-155). Berkeley, CA: University of California Press.

Irwin, T. (Ed.) (1999). Aristotle, Nicomachean Ethics (2nd ed.). Indianapolis, IN: Hackett.

Kenny, A. (1979). Aristotle's theory of the will. London, England: Duckworth.

Klimchuk, D. (2003). Aristotle on intoxication and liability. History of Philosophy Quarterly, 20, 225-243.

Meyer, S. S. (1993). Aristotle on moral responsibility. Oxford, England: Oxford University Press.

Muñoz, A. A. (2002). Liberdade e Causalidade: Ação, responsabilidade e metafísica em Aristóteles. São Paulo, Brazil: Discurso Editorial.

Ramsauer, G. (1878). Aristotelis Ethica Nicomachea. Leipzig, Germany: Teubner.

Roberts, J. (1989). Aristotle on responsibility for action and character. Ancient Philosophy, 9, 23-36.

Roberts, W. R. (Trans.) (1986). Rhetoric. In J. Barnes (Ed.), The complete works of Aristotle (Vol. 2) (pp. 2152-2269). Princeton, NJ: Princeton University Press

Siegler, F. A. (1968). Voluntary and involuntary. The Monist, 52, 268-287. https://doi.org/10.5840/monist196852218

Sorabji, R. (1980). Necessity, cause, and blame. Chicago, IL: University of Chicago Press.

Stewart, J. A. (1892). Notes on the Nicomachean Ethics, 2 vols. Oxford, England: Clarendon Press.

Urmson, J. O. (1991). Aristotle's ethics. London, England: Wiley-Blackwell.

Wolt, D. (2019). The aim of Eudemian Ethics ii 6-9. Ancient Philosophy, 39, 137-149.

Woods, M. (1992). Aristotle, Eudemian Ethics: Books I, II, and VIII. Oxford, England: Oxford University Press.

How to cite this article: Wolt D. Two conceptions of voluntary action in the Nicomachean Ethics. Eur J Philos. 2020;28:292-305. https://doi.org/10.1111/ejop.12486 